\title{
Corneal laceration caused by river crab
}

\author{
Naidu Vinuthinee ${ }^{1,2}$ \\ Anuar Azreen-Redzal' \\ Jaafar Juanarital \\ Embong Zunaina ${ }^{2}$ \\ 'Department of Ophthalmology, \\ Hospital Sultanah Bahiyah, Alor Setar, \\ ${ }^{2}$ Department of Ophthalmology, \\ School of Medical Sciences, Universiti \\ Sains Malaysia, Kubang Kerian, \\ Malaysia
}

This article was published in the following Dove Press journal:

Clinical Ophthalmology

29 January 2015

Number of times this article has been viewed
Abstract: A 5-year-old boy presented with right eye pain associated with tearing and photophobia of 1-day duration. He gave a history of playing with a river crab when suddenly the crab clamped his fingers. He attempted to fling the crab off, but the crab flew and hit his right eye. Ocular examination revealed a right eye corneal ulcer with clumps of fibrin located beneath the corneal ulcer and $1.6 \mathrm{~mm}$ level of hypopyon. At presentation, the Seidel test was negative, with a deep anterior chamber. Culture from the corneal scrapping specimen grew Citrobacter diversus and Proteus vulgaris, and the boy was treated with topical gentamicin and ceftazidime eyedrops. Fibrin clumps beneath the corneal ulcer subsequently dislodged, and revealed a full-thickness corneal laceration wound with a positive Seidel test and shallow anterior chamber. The patient underwent emergency corneal toileting and suturing. Postoperatively, he was treated with oral ciprofloxacin $250 \mathrm{mg}$ 12-hourly for 1 week, topical gentamicin, ceftazidime, and dexamethasone eyedrops for 4 weeks. Right eye vision improved to $6 / 9$ and $6 / 6$ with pinhole at the 2 -week follow-up following corneal suture removal.

Keywords: corneal ulcer, pediatric trauma, ocular injury

\section{Introduction}

Blindness secondary to ocular trauma occurs in approximately half a million people worldwide, ${ }^{1}$ and that affecting the cornea may result in significant ocular morbidity and visual difficulty. ${ }^{2}$ Corneal injuries make up the vast majority of ophthalmic cases seen in emergency departments, both in the pediatric and adult age-groups. ${ }^{3}$ Diagnosing and managing pediatric corneal injuries is much more challenging compared to adult patients, and it is also one of the commonest cases seen in pediatric emergency setting. ${ }^{2}$

Corneal lacerations or perforations are usually caused by high-speed objects flying into the eye. Missiles with stones, catapults, glass, knives, sport-related injuries, and fishing-related injuries are a few of the commonest causes of corneal lacerations that have been reported. ${ }^{4-6}$ Corneal laceration caused by a river crab claw is an unusual case, and to the best of our knowledge it has not been reported in any literature thus far.

Herein, we report a case of corneal laceration caused by a river crab. Close monitoring of the patient is important, as physical findings may be misleading and would result in poor visual outcome, especially in the pediatric age-group.

\section{Case report}

A healthy 5-year-old boy presented with right eye pain associated with tearing and photophobia of 1 day's duration. He was playing with a river crab when suddenly the crab clamped his fingers. He tried to fling the crab off, but the crab flew and hit his right eye. Following the incident, he developed pain over the right eye associated with 
excessive tearing, photophobia, and poor vision. However, there were no floaters, flashes of light, or curtain field defects. According to his father, he had good premorbid vision in both eyes prior to the incident.

He was not cooperative for the vision test over the affected eye. However, fellow eye vision was 6/6. There was an absence of reverse relative afferent pupillary defect. Slit-lamp examination of the right eye revealed generalized injected conjunctiva. There was a cornea ulcer centrally obscuring the visual axis region measuring $1.4 \mathrm{~mm}$ horizontally and $1.0 \mathrm{~mm}$ vertically (Figure 1). The base of the corneal ulcer was clean, with a clear margin. There were fibrin clumps located beneath the corneal ulcer with hypopyon in the anterior chamber (Figure 1). The hypopyon level was measured at $1.6 \mathrm{~mm}$ in height. However, there were no infiltrates or satellite lesion noted. The Seidel test was negative, and the anterior chamber was deep. The view of the iris and lens details was obscured. The fundus view was very hazy. A B-scan revealed a flat retina with a clear vitreous. Left eye examination was normal.

He was diagnosed with corneal ulcer of the right eye, most probably secondary to bacterial infection following trauma. He was treated with topical $0.9 \%$ gentamicin and $5 \%$ ceftazidime eyedrops hourly after performing corneal scrapping.

On the day following the injury, the fibrin clumps beneath the corneal ulcer got dislodged and revealed a full-thickness corneal laceration wound centrally (Figure 2). The full-thickness corneal laceration wound was $1.4 \mathrm{~mm}$ in length across the visual axis. The anterior chamber was noted to be very shallow, with fibrin clumps located in the superotemporal region and disappearance of the hypopyon. The Seidel test was positive, with fast oozing out of the aqueous.

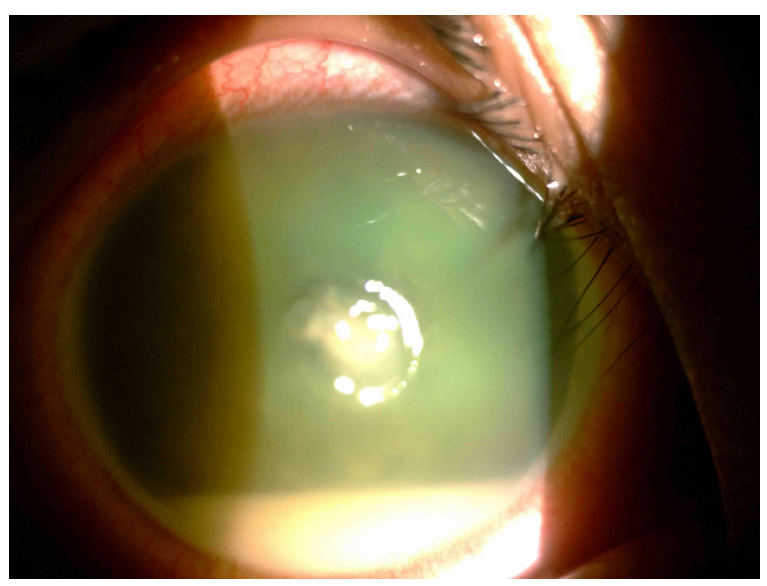

Figure I Right eye showing corneal ulcer centrally with hypopyon.

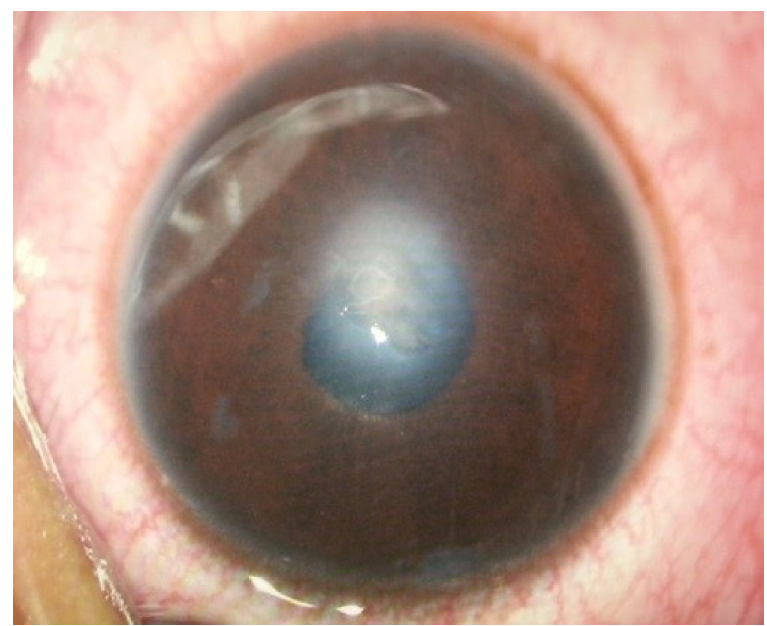

Figure 2 Right eye showing full thickness corneal laceration wound centrally with fibrin clumps in the anterior chamber located superotemporally.

He was then diagnosed as having a right eye full-thickness corneal laceration wound with severe traumatic uveitis secondary to trauma. He underwent right eye examination under general anesthesia, and the corneal laceration was repaired with 10/0 nylon sutures.

Postoperatively, the patient was treated with topical $0.3 \%$ gentamicin, $5 \%$ ceftazidime, and $0.1 \%$ dexamethasone eyedrops, in addition to oral ciprofloxacin $250 \mathrm{mg}$ 12-hourly for a week. Culture from the corneal scrapping specimen grew Citrobacter diversus and Proteus vulgaris, which were sensitive to gentamicin and ceftazidime. The anterior-chamber inflammation resolved completely over several days. A week later, visual acuity in the right eye had improved to $6 / 36$ and $6 / 12$ with pinhole.

The topical gentamicin eyedrops were discontinued after 2 weeks. The topical ceftazidime and dexamethasone eyedrops were tapered slowly within the next 4 weeks. Corneal sutures were completely removed at 8 weeks postoperation. At 2 weeks post-suture removal, subjective refraction revealed right eye best-corrected vision of $6 / 9$ and $6 / 6$ with pinhole. The right eye showed a white conjunctiva, with a central thin corneal scar. The anterior chamber was quiet, with a clear lens.

\section{Discussion}

Trauma involving the cornea can be a devastating injury to the eye, and causes a significant visual difficulty and ocular morbidity. ${ }^{2,7}$ Penetrating corneal injuries are one of the commonest form of ocular trauma seen at the emergency department, and they can vary from a small perforation to an extensive laceration. ${ }^{2}$ It has been reported that $6.8 \%-14.7 \%$ of ocular traumatic injuries that present at emergency 
departments are corneal lacerations and perforations, ${ }^{8-10}$ and these are the commonest finding in the pediatric age-group..$^{4,11}$ Omobolanle et al found that males have a higher incidence of corneal lacerations compared to females, with a ratio of approximately $3: 1$ and mean age of 8.7 years. ${ }^{4}$

Common symptoms of patients with corneal laceration include severe pain, tearing, photophobia, blurring or reduced vision, foreign-body sensation, and sometimes blood in the eye. Detecting, diagnosing, triaging, and deciding on the treatment should be done as soon as possible to achieve the best result and outcome. ${ }^{12}$ Culturing of the wound site is imperative if there are suspicions of an infectious etiology, ${ }^{13}$ which we did for our patient, as river crabs are present in soil and water that may be contaminated with organisms. In our patient, the culture grew Citrobacter diversus and Proteus vulgaris.

Our patient probably sustained an injury to the cornea from the claws of the river crab when he was trying to swing the crab away from his clamped finger. Following that, an acute inflammatory reaction set in, probably secondary to the impact of the trauma (perforation and concussion), and resulted in anterior-chamber exudation, and this intense inflammation sealed the lacerated corneal wound temporarily when he was seen shortly after the injury. Somehow, the clumped fibrin dislodged the following day, revealing a full-thickness corneal laceration wound.

The treatment of corneal laceration has evolved over the years, both medically and surgically. The standard surgical management for corneal laceration is still the interrupted $10-0$ nylon, which is able to oppose the anterior and posterior edges well without any override or underride. However, placing a suture for a central corneal laceration interferes with vision, and the tension that sutures exert on tissue to pull it together may create irregular astigmatism. Also, unlike a sealant or glue, which forms a continuous bond, sutures are spaced apart and create a bond that is weaker in some areas than others. Aukerman et al mentioned that tissue adhesives in repairing superficial, linear, and low-tension lacerations are effective, and have proven results comparable to those with conventional suturing. ${ }^{14}$ Velazquez et al suggested that either method of closure, adhesive or suture, is able to withstand the physiologic increases in intraocular pressure postoperatively, and that biodendrimer adhesives are able to seal large corneal lacerations. ${ }^{15}$

Given that tissue adhesive can be very costly, several cases are scheduled together to save cost. In our patient, it was an emergency and his parents were unable to afford the cost of tissue adhesive, so we proceeded with suturing. However, the primary goal of initial repair is to restore the integrity of the globe, thus preventing hypotony and infection, and the secondary goal, which can be achieved during the primary repair or secondary procedures, is to restore vision by means of repairing damaged intraocular structures. ${ }^{10}$

Corneal lacerations and perforations, especially in the pediatric age-group, are significantly challenging, ${ }^{2}$ right from the time the child presents at the eye clinic, through diagnosing, treatment, management, and compliance with therapy, ${ }^{16}$ to follow-up and finally visual rehabilitation and the outcome. Corneal laceration is unlikely to cause mortality, but can result in significant morbidity. ${ }^{6}$ Common associated complications are astigmatism due to corneal sutures and subsequent scarring, corneal opacity, and amblyopia. With the current alternative suture techniques and proper understanding of the cornea's refractive properties via topography, we were able to restore corneal curvature to its best. ${ }^{17}$ Navon concluded that after suture removal, the cornea regains almost normal contour due to its unique topographic memory. ${ }^{18}$ In order to prevent amblyopia, early correction of refractive error, reestablishing a clear media, and ensuring the use of injured eye by patching the normal eye are very important. $^{2}$

However, the management and prognosis of corneal lacerations varies, and strongly depends on the nature of the object involved and the wound characteristics, site and extent of the wound, time of presentation and treatment started, and other associated ocular injuries, such as lens opacity, vitreous hemorrhage, retinal detachment, limbal-scleral laceration with uveal tissue prolapse, lid laceration, and optic nerve avulsion. ${ }^{3,4}$

If not treated promptly, ocular trauma in children can result in development of intractable amblyopia. Our patient required only primary repair, and achieved almost excellent visual recovery. Many factors play an important role in managing corneal trauma in order to prevent poor vision. Besides that, by educating parents and caregivers in the importance of supervising children while they play and immediate action when trauma takes place is important in optimizing visual outcomes. $^{4}$

\section{Disclosure}

The authors report no conflicts of interest in this work.

\section{References}

1. Thylefors B. Epidemiological patterns of ocular trauma. Aust $N Z J$ Ophthalmol. 1992;20(2):95-98.

2. Vora GK, Haddadin R, Chodosh J. Management of corneal lacerations and perforations. Int Ophthalmol Clin. 2013;53(4):1-10.

3. Aslam SA, Sheth HG, Vaughan AJ. Emergency management of corneal injuries. Injury. 2007;38(5):594-597. 
4. Omobolanle AA, Henrietta N. Pattern of paediatric corneal laceration injuries in the University of Port Harcourt teaching hospital, Rivers State, Nigeria. BMC Res Notes. 2012;5:683.

5. Aritürk N, Sahin M, Oge I, Erkan D, Süllü Y. The evaluation of ocular trauma in children between ages 0-12. Turk J Pediatr. 1999;41(1): 43-52.

6. Alfaro DV 3rd, Jablon EP, Rodriguez Fontal M, et al. Fishing-related ocular trauma. Am J Ophthalmol. 2005;139(3):488-492.

7. Strahlman E, Elman M, Daub E, Baker S. Causes of pediatric eye injuries. A population-based study. Arch Ophthalmol. 1990;108(4):603-606.

8. Oum BS, Lee JS, Han YS. Clinical features of ocular trauma in emergency department. Korean J Ophthalmol. 2004;18(1):70-78.

9. Kaimbo WK, Spileers W, Missotten L. Ocular emergencies in Kinshasa (Democratic Republic of Congo). Bull Soc Belge Ophtalmol. 2002;284: 49-53.

10. Hamill MB. Corneal and scleral trauma. Ophthalmol Clin North Am. 2002;15(2):185-194.

11. Liu ML, Chang YS, Tseng SH, et al. Major pediatric ocular trauma in Taiwan. J Pediatr Ophthalmol Strabismus. 2010;47(2):88-95.

12. McMahon TT, Robin JB. Corneal trauma: I - Classification and management. J Am Optom Assoc. 1991;62(3):170-178.
13. Lin DT, Webstar RG Jr, Abbott RL. Repair of corneal lacerations and perforations. Int Ophthalmol Clin. 1988;28(1):69-75.

14. Aukerman DF, Sebastianelli WJ, Nashelsky J. Clinical inquiries. How does tissue adhesive compare with suturing for superficial lacerations? J Fam Pract. 2005;54(4):378.

15. Velazquez AJ, Carnahan MA, Kristinsson J, Stinnett S, Grinstaff MW, Kim T. New dendritic adhesives for sutureless ophthalmic surgical procedures: in vitro studies of corneal laceration repair. Arch Ophthalmol. 2004;122(6):867-870.

16. Hosseini H, Masoumpour M, Keshavarz-Fazl F, Razeghinejad MR, Salouti R, Nowroozzadeh MH. Clinical and epidemiologic characteristics of severe childhood ocular injuries in Southern Iran. Middle East Afr J Ophthalmol. 2011;18(2):136-140.

17. Macsai MS. The management of corneal trauma: advances in the past twenty-five years. Cornea. 2000;19(5):617-624.

18. Navon SE. Topography after repair of full-thickness corneal laceration. J Cataract Refract Surg. 1997;23(4):495-501.
Clinical Ophthalmology

\section{Publish your work in this journal}

Clinical Ophthalmology is an international, peer-reviewed journal covering all subspecialties within ophthalmology. Key topics include: Optometry; Visual science; Pharmacology and drug therapy in eye diseases; Basic Sciences; Primary and Secondary eye care; Patient Safety and Quality of Care Improvements. This journal is indexed on

\footnotetext{
Submit your manuscript here: http://www.dovepress.com/clinical-ophthalmology-journal
}

\section{Dovepress}

PubMed Central and CAS, and is the official journal of The Society of Clinical Ophthalmology (SCO). The manuscript management system is completely online and includes a very quick and fair peer-review system, which is all easy to use. Visit http://www.dovepress.com/ testimonials.php to read real quotes from published authors. 